\title{
The Association of Stress with the Socio-Economic Factors of Individuals That Attended the Taxpayers' Appreciation Week 2018, Kampala Uganda
}

\author{
${ }^{1}$ Faculty of Health Science, Victoria University, Kampala, Uganda \\ ${ }^{2}$ Public Health Department, Victoria University, Kampala, Uganda \\ ${ }^{3}$ Nutrition Department, Victoria University, Kampala, Uganda \\ ${ }^{4}$ Faculty of Humanities and Social Sciences, Victoria University, Kampala, Uganda \\ ${ }^{5}$ Nursing Department, Victoria University, Kampala, Uganda \\ ${ }^{6}$ Midwifery Department, Victoria University, Kampala, Uganda \\ Email: "uchenwanna1@gmail.com, uche4score@yahoo.com
}

Nwanna Uchechukwu Kevin ${ }^{1 * \#, ~ N a b u n y a ~ M a r i a h ~ P e g g y ², ~ R e b e c c a ~ S u u b i ~}{ }^{3}$, Ilori Oluwole², Kalyango Frank ${ }^{2}$, Fred Kasirye ${ }^{4}$, James Kateregga ${ }^{5}$, Jimmy Kirumira ${ }^{5}$, Carol Nabasirye ${ }^{6}$

How to cite this paper: Kevin, N.U., Peggy, N.M., Suubi, R., Oluwole, I., Frank, K., Kasirye, F., Kateregga, J., Kirumira, J. and Nabasirye, C. (2020) The Association of Stress with the Socio-Economic Factors of Individuals That Attended the Taxpayers' Appreciation Week 2018, Kampala Uganda. Journal of Behavioral and Brain Science, 10, 562-567.

https://doi.org/10.4236/jbbs.2020.1012035

Received: October 17, 2020

Accepted: December 15, 2020

Published: December 18, 2020

Copyright $\odot 2020$ by author(s) and Scientific Research Publishing Inc. This work is licensed under the Creative Commons Attribution International License (CC BY 4.0).

http://creativecommons.org/licenses/by/4.0/ (c) (i) Open Access

\begin{abstract}
Introduction: Work-related stress has increased in nine European Union (EU) countries in the last ten years. Eighty (80\%) percent of the general population in European countries believes that work-related stress will rise in the coming five years. Objective: The purpose of this study was to determine the association between the various levels of stress with the socio-economic elements among individuals that participated in Uganda's tax payer's appreciation week in the year 2018 held in Kampala. Methodology: This study applied a cross-sectional study design that unified quantitative research methods and a convenience sampling method were used in this study to gather the information from the 390 respondents. Data were examined using SPSS version 20; univariate and bivariate analysis were done to measure the association between stress and the participant's socio-economic factors. Results: Respondents who were employed recorded the majority with a percentage of $60 \%$, while the unemployed recorded the minority with a percentage of $40 \%$. Respondents who were employed were more likely to experience low stress as compared to those who were unemployed, under the category of moderate stress, respondents who were employed were more likely to be moderately stressed as compared to their unemployed counterparts, as for the category of high stress, unemployed respondents were more likely to be highly stressed than those that were employed and this was not statistically significant $\left(\mathrm{X}^{2}=\right.$
\end{abstract}

${ }^{*}$ Main Author; ${ }^{\sharp}$ Corresponding Author. 
2.374; $\mathrm{p}$-value $=0.305)$. Conclusion: The results from this research indicated that there was no significant association between the socioeconomic factors of the respondents with stress levels. Recommendations: More community sensitization and awareness should be carried out to educate individuals about stress and its impacts on health.

\section{Keywords}

Socio-Economic, Uganda, Work-Related Stress

\section{Introduction}

Kortum, E., et al., (2010) [1] reported that work-related stress has increased in nine European Union (EU) countries in the last ten years. Eighty (80\%) percent of the general population in European countries believe that work-related stress will rise in the coming five years. According to a study carried out by Erschens, R., et al. (2018) [2] on the prevalence of perceived stress, the study showed that most of the participants were employed.

According to a study by Ayesha Khalid, et al. (2013) [3] on stress levels among call centres employees, the results showed that stress levels of women did not differ significantly from men. The study also shows that level of stress was significantly higher in night shift employees as compared to today shift employees and employees of inbound call centres have significantly higher levels of stress as compared to employees of outbound call centres. Paoli, P. (1997) [4] stated that the incidence of stress within European society is on the rise and accounts for over thirty (30\%) percent of all absence from work. Research on the prevalence of Posttraumatic Stress Disorder (PTSD) is still limited in low-income countries yet PTSD is a public health problem in post-conflict areas.

Currently, over $78 \%$ of Uganda's population is below 30 years of age [5]. This group of people is very susceptible to mental health issues due to lack of preventive measures and therefore needs to have good health and mental stability to increase the country's productivity which will, in turn, favor the country's economy.

According to a study carried by Dwamena, M.A., 2012 [6] on stress and its effects on employees' productivity, various stress factors hindered and lowered the productivity of employees in Ghana. Some of them include employees feeling like they're not being treated fairly, having dissatisfaction with the work environment, determining whether employees have control over their jobs, exploring work pressure and role clarity, and exploring whether employees participate in decision making among many others. Results of the study showed that the majority (55\%) of the respondents reported that they do not think that Ghana Ports and Harbors Authority (GPHA) cares for them, only sixteen percent (16\%) reported satisfaction with the working conditions of the organization and forty-nine percent (49\%) reported emphasis on "sometimes not satisfied with the work environment". Reports on whether the 
employees had control over their jobs showed that only thirty-eight (38) percent sometimes had control over their jobs and eighteen (18) percent did not have any control over their jobs. The lack of control over one's job may potentially cause frustration because of uncertainties and in the long run, lead to being stressed.

\section{Methodology}

\subsection{Research Design}

This study applied a cross-sectional study design that made use of a quantitative research method of inquiry.

\subsection{Study Population and Location}

The study included individuals from both genders who attended the Taxpayers' Appreciation week in Kampala Uganda in the year 2018.

\subsection{Sample Size}

This was determined by the number of individuals that enrolled for the research study while at the tent that was set up during the Taxpayers' Appreciation week celebrations 2018.

\subsection{Sampling Strategies and Procedures}

The convenience sampling technique was utilized in this research study to collect relevant data from the respondents. The respondents in this study were gotten based on based on convenience. The research team set up a tent for different tests to be done and upon arrival; individuals were told about the on-going study and were requested to participate. Only those who consented took part in this study. The consent process was written in the questionnaire.

\subsection{Inclusion Criteria}

This research study included a cross-section of individuals that attended the Taxpayers' Appreciation week celebrations in 2018.

\subsection{Exclusion Criteria}

This research study decided to exclude all under-fives that attended the Taxpayers' Appreciation week in Kololo Airstrip Kampala Uganda in the year 2018.

\subsection{Data Collection Methods}

A structured and vetted questionnaire was adopted to obtain relevant data from the individuals using only the quantitative method of inquiry.

\subsection{Measurement of Variables}

\subsubsection{Independent Variables}

Socio-economic factors: Attributes such as being employed and being unem- 
ployed were controlled by using essential questions related to each attribute.

\subsubsection{Dependent Variable}

Stress Levels: Attributes such as low stress, moderate stress, and high stress were controlled by using essential questions related to each attribute.

\subsection{Data Analysis}

Data collected were analysed using SPSS version 20. Uni-variate and Bi-variate analyses were done to analyse the data. The bivariate analysis made use of Pearson's Chi-square to establish a significant association between socioeconomic factors and stress at an alpha level of 0.05 .

\subsection{Ethical Considerations}

An approval letter to carry out the study was obtained from the Victoria University Uganda research and ethical committee. All participants were treated with dignity and respect. Confidentiality and anonymity were guaranteed to the participant by using codes for identification instead of their names.

\subsection{Limitation of the Study}

Study design which led to information bias in some cases-I overcame this by diligently persuading the respondents to supply the correct information.

However, the results of this research study are limited to an observed relationship.

\section{Results}

\subsection{Uni-Variate Analysis}

The employed respondents were classified as people who earn a monthly/weekly/ daily income; whereas the unemployed were classified as those who were solely dependent on others for their needs.

From the table above; respondents who were employed recorded the majority (234), while the unemployed recorded the minority (156) (Table 1).

From Figure 1, the majority of the respondents were employed (60\%).

However, the major age group of respondents was between $21-25$ years (24.1\%), while the minority was 15 years and below $(0.8 \%)$.

The gender ratio (male:female) was 1:1.

\subsection{Bi-Variate Analysis}

From the table above, respondents who were employed were more likely to experience low stress as compared to those who were unemployed, under the category of moderate stress, the respondents who were employed were more likely to be moderately stressed as compared to their unemployed counterparts, as for the category of high stress, unemployed respondents were more likely to be highly stressed than those that were employed and this was not statistically significant $\left(\mathrm{X}^{2}=2.374 ; \mathrm{p}\right.$-value $\left.=0.305\right)($ Table 2$)$. 


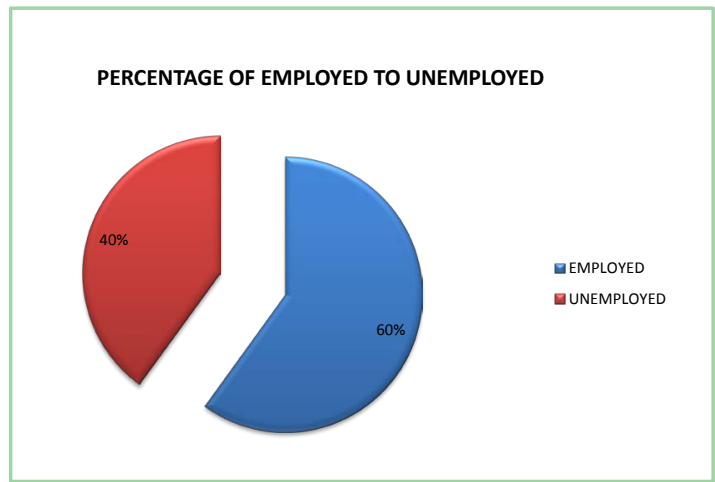

Figure 1. Percentage of employed to unemployed respondents.

Table 1. Socioeconomic factors of the respondents.

\begin{tabular}{ccc}
\hline \multicolumn{3}{c}{ Socioeconomic Factors of the respondents } \\
\hline No. & Variable & Frequency $(\mathbf{n}=390)$ \\
\hline 1. & Employed & 234 \\
2. & Unemployed & 156 \\
\hline
\end{tabular}

Table 2. Socioeconomic Factors of the respondents associated with stress levels.

\begin{tabular}{ccccccc}
\hline No: & Variable & $\begin{array}{c}\text { Low } \\
\text { Freq. (\%) }\end{array}$ & $\begin{array}{c}\text { Moderate } \\
\text { Freq. (\%) }\end{array}$ & $\begin{array}{c}\text { High } \\
\text { Freq. (\%) }\end{array}$ & $\begin{array}{c}\text { Chi-square } \\
\left(\mathbf{x}^{2}\right)\end{array}$ & p-value \\
\hline 1. & Employed & $51(21.8 \%)$ & $132(56.4 \%)$ & $51(21.8 \%)$ & & \\
2. & Unemployed & $28(17.9 \%)$ & $84(53.8 \%)$ & $44(28.2 \%)$ & & 0.305 \\
\hline
\end{tabular}

\section{Discussion}

From this research study, none of the variables under socioeconomic factors (employed and unemployed) were statistically significant with stress levels; this might be because of lack of follow-up of the respondents in this research study. These results were not in line with the results from Baum, A., et al. (1999) [7] that stated that socioeconomic factors affect stress levels, whereby people from lower socioeconomic status (SES) groups may experience more distress and poorer health outcomes because they cannot purchase goods or services that reduce stress, minimize sources of stress, or that can be used to prevent or treat illnesses. This was also not in line with results from Yang, T., et al. (2017) [8] that stated that most SES variables were associated with uncertainty stress;

\section{Conclusion}

The results from this research indicated that there was no significant association between the socioeconomic factors of the respondents with stress levels. However, further research on stress in all works of life and occupations with a larger population should be carried out to bridge the gap on the paucity of data on stress in low-income countries; this will enable various individuals to make informed and right decisions concerning their health. 


\section{Recommendation}

More community sensitization and awareness should be done to educate individuals about stress, its impacts on health, the causes of stress, and how to prevent it so that people become more aware of the issue and therefore take the right measures to prevent it.

\section{Conflicts of Interest}

The authors declare no conflicts of interest regarding the publication of this paper.

\section{References}

[1] Kortum, E., Leka, S. and Cox, T. (2010) Psychosocial Risks and Work-Related Stress in Developing Countries: Health Impact, Priorities, Barriers, and Solutions. International Journal of Occupational Medicine and Environmental Health, 23, 225-238. https://doi.org/10.2478/v10001-010-0024-5

[2] Erschens, R., Herrmann-Werner, A., Keifenheim, K.E., Loda, T., Bugaj, T.J., Nikendei, C., Lammerding-Köppel, M., Zipfel, S. and Junne, F. (2018) Differential Determination of Perceived Stress in Medical Students and High-School Graduates Due to Private and Training-Related Stressors. PloS One, 13, e0191831. https://doi.org/10.1371/journal.pone.0191831

[3] Khalid, A., Sarfaraz, A., Ahmed, S., and Malik, F. (2013) Prevalence of Stress among Call Center Employees. Pakistan Journal of Social and Clinical Psychology, 11, 58-62.

[4] Paoli, P. (1997) Second European Survey on Working Conditions 1996. Ireland: European Foundation for the Improvement of Living and Working Conditions, Dublin.

[5] United Nations High Commissioner for Refugees (2015) Uganda Country Refugee Response Plan. The Integrated Response Plan for Refugees from South Sudan, Burundi and the Democratic Republic of the Congo. January 2019-December 2020.

[6] Dwamena, M.A. (2012) Stress and Its Effects on Employees Productivity-A Case Study of Ghana Ports and Harbors Authority, Takoradi. Doctoral Dissertation, Kwame Nkrumah University of Science and Technology, Kumasi.

[7] Baum, A., Garofalo, J.P. and Yali, A.M. (1999) Socioeconomic Status and Chronic Stress: Does Stress Account for SES Effects on Health? Annals of the New York Academy of Sciences, 896, 131-144. https://doi.org/10.1111/j.1749-6632.1999.tb08111.x

[8] Yang, T., Yang, X.Y., Yu, L., Cottrell, R.R. and Jiang, S. (2017) Individual and Regional Association between Socioeconomic Status and Uncertainty Stress, and Life Stress: A Representative Nationwide Study of China. International Journal for Equity in Health, 16, Article No.118. https://doi.org/10.1186/s12939-017-0618-7 